\title{
The report and analysis concerning the usefulness of basic telemedicine tools in the skin cancer diagnostic screening process during COVID-19 pandemics
}

\author{
Marcin Ziętek ${ }^{1,2}$, Maciej Nowacki ${ }^{1,3}$, Jędrzej Wierzbicki ${ }^{4}$, Rafał Matkowski ${ }^{1,2}$, Adam Maciejczyk ${ }^{1,2}$, Rafał Czajkowski ${ }^{5}$, \\ Edyta Pawlak-Adamska ${ }^{6}$
}

\author{
${ }^{1}$ Wroclaw Comprehensive Cancer Center, Wroclaw, Poland \\ 2Department of Oncology, Wroclaw Medical University, Wroclaw, Poland \\ ${ }^{3}$ Chair of Surgical Oncology, Ludwik Rydygier Collegium Medicum in Bydgoszcz, Nicolaus Copernicus University in Torun, Poland \\ ${ }^{4}$ SSG Group, Ludwik Rydygier Collegium Medicum in Bydgoszcz, Nicolaus Copernicus University in Torun, Poland \\ ${ }^{5}$ Department of Dermatology and Venereology, Faculty of Medicine, Ludwik Rydygier Medical College in Bydgoszcz, \\ Nicolaus Copernicus University in Torun, Poland \\ ${ }^{6}$ Department of Experimental Therapy, Hirszfeld Institute of Immunology and Experimental Therapy, Wroclaw, Poland
}

Adv Dermatol Allergol 2022; XXXIX (1): 189-194

DOI: https://doi.org/10.5114/ada.2022.113605

\begin{abstract}
Introduction: A rapid spread of the emerging COVID-19 pandemic limited the availability of professional medical advice. As a result, a significant increase in the number of undiagnosed and chronically ill patients without medical care was noticed. In reaction to the urgent need, the telemedical consultation, instead of the classical form, may be introduced as a vulnerable tool in preclinical evaluation of patients with potentially malignant skin lesions. Aim: In this study the results of the implementation of telemedical consultation programme with the intention to early detect the skin cancers in patients who, due to the COVID-19 pandemic, could not undergo the standard consultation was presented.

Material and methods: The programme of remote dermatological consultation, which was introduced on 1 June 2020 , covered all patients who had no possibility or will to visit the standard healthcare units. In case of suspicion of life-threatening skin lesions patients were invited for additional diagnostics or surgery. Obtained data, including demography, age, surgery description and pathomorphological examination were descriptively analysed.

Results: In total, 80 consecutive patients were enrolled during the screening programme. In total, 31 lesions in 25 patients were excised. In this group there were 10 serious diagnoses including 5 cases of basal cell carcinoma, melanoma in situ and dysplastic nevi. Moreover, another 10 patients were referred to other specialists or specific recommendations were advised.

Conclusions: An alternative track using teledermatology for patients with skin diseases was successfully introduced under the specific conditions of epidemiologic danger. Despite its disadvantages teledermatology enabled the diagnosis and treatment in a significant number of serious cases.
\end{abstract}

Key words: teledermatology, telemedical consultation, COVID-19, melanoma screening programme.

\section{Introduction}

At the end of 2019, and in Europe at the beginning of 2020, the new SARS-CoV-2 coronavirus causing the disease called by WHO as COVID-19 paralyzed not only the global economy and interpersonal relations, but also significantly reduced the ability of individual medical systems to diagnose and treat other, mainly chronic and severe diseases [1, 2]. In many countries, this situation occurred due to the significant burden on national health systems operating on the edge of its potential or the introduction of lockdowns [3]. In response to this phenomenon, many centres began to search very quickly for various options, including those based on the achievements of telemedicine, which would avoid the lack of optimal diagnosis, progression and treatment of

Address for correspondence: Marcin Ziętek MD, PhD, Wroclaw Comprehensive Cancer Center, Department of Oncology, Wroclaw Medical University, Wroclaw, Poland, e-mail: zietekm@op.pl Received: 23.11.2020, accepted: 29.01.2021. 
different serious chronic diseases [4]. The introduction of telemedicine resulted in a consultation increase in some centres in March and April 2020 by almost $700 \%$ [5]. Moreover, in the field of dermatopathology, in some cases like in Genoa smartworking programme the periodic follow-up procedures designed for care of chronic, severe, inflammatory skin patients became the only and rational method of consultation [6]. However, despite such quick implementation of telemedicine, a serious problem was faced by a large group of previously undiagnosed patients with suspicious skin lesions who required appropriate screening triage and diagnostics. Due to closed clinics or limited access to them or even scientifically proven personal fear of contracting coronavirus in a medical facility, patients were suddenly excluded from standard diagnostic protocols [7, 8].

\section{Aim}

The aim of this study was to present a results of a single centre effective implementation of standard telemedical screening programme procedures designed for early detection of potential skin cancer lesions in a group of patients which due to the COVID-19 pandemics could not or will not undergo the standard live clinical ambulatory consultation.

\section{Material and methods}

\section{Screening design and their implementation}

In response to the increasing number of diagnoses of COVID-19 cases in Europe and in Poland, as well as due to the introduced lockdown and the high risk of such restrictions repetition, during the so-called second COVID-19 wave of autumn 2020, from March to June 2020, the Second Department of Surgical Oncology of Lower Silesian Oncology Center in Wroclaw in Poland was developing the possibility of implementing an alternative diagnostic track for people who would like to consult their suspected skin lesions and who, due to the pandemic, either could not or did not want to personally appear at a classic medical consultation. During the preparatory analyses, it was decided to implement the simplest, most accessible and easiest-touse telemedicine solutions in the screening programme. It was dictated by the desire to reach the largest group of potential patients of all ages from various socio-social backgrounds. At the beginning, all possible IT elements limiting access to the consultation or "discouraging" the potential user were excluded. So it was decided to exclude the need for tedious registration, login and password creation, or transfer between pages and portals. The creation team decided to use the simplest method, which means the use of an email address on the encrypted and secured Oncology Center portal and server to which a potential patient could send the necessary data in the fastest way from his/her Smartphone, tablet or PC. In order to reduce spam or send- ing content unrelated to the subject of the study, appropriate IT blocking and filtering solutions were introduced.

The first of July 2020 was set as an initiation date of the remote screening consultation programme. In order to provide information and obtain the most clinically valuable data, the period from June to July 2020 was spent for information campaigns which were conducted in social media and regional television. Potential patients were informed in those campaigns that they should send, to the email address, several differently zoomed and well-lighted photos from different perspectives of any skin changes they would like to consult with additional personal data. Age, place of residence, personal identity number (PESEL) and social security number were requested to provide us with anamnestic disease data (chronic diseases, previous treatment, etc.). The programme is intended only for people who have not been treated because of skin cancer at all, and such people were asked to use classical medical solutions.

However, the most important and key element was information that it is a pilot programme and all patients covered will be later invited for standard medical consultations with all patient and staff protection pandemic procedures to assess the reliability of this screening method and to eliminate potentially false diagnoses.

\section{Statistical analysis}

Statistica 13.3 software (TIBCO Software Inc., California, United States) was used to perform statistical analysis. Based on gender, age and demography, a multi-way frequency table showing patients' place of residence was prepared. Additional diagnostic procedures enrolled patients underwent and diagnosed lesions were retrospectively analysed based on received data. To compare the mean age of men and women who needed surgical intervention student's $t$-test for independent samples was used. A p-value below 0.05 was considered significant. Excised lesions were assessed by pathologists and the results were presented in a pie chart form.

\section{Results}

\section{Study group}

Between 1 June and 27 August 2020, 80 consecutive patients, of whom 50 were women and 30 men, applied to the telemedical consultation programme via the website of the Wroclaw Comprehensive Cancer Center. Six of them did not include relevant clinical data (e.g. past medical history, associated symptoms) or photographs in the message and ultimately these cases were not further assessed. Mean age of the enrolled patients for men and women was 43.29 (age range: $14-81$ ) and 44.70 (age range: 9-96), respectively and 44.2 in total. Patients' place of residence was summarized in Table 1. Patients from the entire Wroclaw poviat, including Wroclaw city and agglomeration, were the most numerous 
Table 1. Characteristics of patients demography in different age groups

\begin{tabular}{|c|c|c|c|c|c|c|c|c|c|c|c|}
\hline $\begin{array}{l}\text { Age } \\
\text { group }\end{array}$ & Sex & Wroclaw & $\begin{array}{l}\text { Wroclaw } \\
\text { agglome- } \\
\text { ration }\end{array}$ & $\begin{array}{l}\text { Wroclaw } \\
\text { poviat }\end{array}$ & $\begin{array}{l}\text { Lower } \\
\text { Silesia }\end{array}$ & $\begin{array}{l}\text { Opole } \\
\text { Voivo- } \\
\text { deship }\end{array}$ & $\begin{array}{l}\text { Greater } \\
\text { Poland }\end{array}$ & $\begin{array}{l}\text { Lesser } \\
\text { Poland }\end{array}$ & Silesia & $\begin{array}{l}\text { Lublin } \\
\text { Voivo- } \\
\text { deship }\end{array}$ & Germany \\
\hline \multirow[t]{2}{*}{$<30$} & $\mathrm{~F}$ & $\begin{array}{c}7 \\
(8.75 \%)\end{array}$ & & & $\begin{array}{c}1 \\
(1.25 \%)\end{array}$ & & $\begin{array}{c}2 \\
(2.50 \%) \\
\end{array}$ & $\begin{array}{c}1 \\
(1.25 \%)\end{array}$ & & & \\
\hline & M & $\begin{array}{c}3 \\
(3.75 \%)\end{array}$ & $\begin{array}{c}1 \\
(1.25 \%)\end{array}$ & $\begin{array}{c}1 \\
(1.25 \%)\end{array}$ & & $\begin{array}{c}1 \\
(1.25 \%)\end{array}$ & & & & & \\
\hline \multirow[t]{2}{*}{$30-39$} & $\mathrm{~F}$ & $\begin{array}{c}10 \\
(12.50 \%)\end{array}$ & $\begin{array}{c}1 \\
(1.25 \%)\end{array}$ & $\begin{array}{c}1 \\
(1.25 \%)\end{array}$ & & $\begin{array}{c}2 \\
(2.50 \%)\end{array}$ & & & & & \\
\hline & M & $2(2.50 \%)$ & $\begin{array}{c}1 \\
(1.25 \%)\end{array}$ & $\begin{array}{c}1 \\
(1.25 \%) \\
\end{array}$ & $\begin{array}{c}2 \\
(2.50 \%) \\
\end{array}$ & & $\begin{array}{c}1 \\
(1.25 \%)\end{array}$ & $\begin{array}{c}1 \\
(1.25 \%)\end{array}$ & $\begin{array}{c}1 \\
(1.25 \%)\end{array}$ & & \\
\hline \multirow[t]{2}{*}{$40-49$} & $\mathrm{~F}$ & $\begin{array}{c}4 \\
(5.00 \%)\end{array}$ & & $\begin{array}{c}3 \\
(3.75 \%)\end{array}$ & $\begin{array}{c}2 \\
(2.50 \%)\end{array}$ & & & & & & $\begin{array}{c}1 \\
(1.25 \%)\end{array}$ \\
\hline & $M$ & $\begin{array}{c}6 \\
(7.5 \%)\end{array}$ & $\begin{array}{c}1 \\
(1.25 \%)\end{array}$ & & & & & & & $\begin{array}{c}1 \\
(1.25 \%)\end{array}$ & \\
\hline \multirow[t]{2}{*}{$50-59$} & $\mathrm{~F}$ & & & & $\begin{array}{c}3 \\
(3.75 \%) \\
\end{array}$ & $\begin{array}{c}1 \\
(1.25 \%)\end{array}$ & & & & & \\
\hline & M & & & $\begin{array}{c}1 \\
(1.25 \%)\end{array}$ & $\begin{array}{c}1 \\
(1.25 \%)\end{array}$ & & & & & & \\
\hline \multirow[t]{2}{*}{$60+$} & $\mathrm{F}$ & $\begin{array}{c}7 \\
(8.75 \%)\end{array}$ & $\begin{array}{c}1 \\
(1.25 \%)\end{array}$ & $\begin{array}{c}1 \\
(1.25 \%)\end{array}$ & $\begin{array}{c}1 \\
(1.25 \%)\end{array}$ & $\begin{array}{c}1 \\
(1.25 \%)\end{array}$ & & & & & \\
\hline & $M$ & $\begin{array}{c}2 \\
(2.50 \%)\end{array}$ & $\begin{array}{c}1 \\
(1.25 \%) \\
\end{array}$ & & & $\begin{array}{c}1 \\
(1.25 \%)\end{array}$ & $\begin{array}{c}1 \\
(1.25 \%)\end{array}$ & & & & \\
\hline Total & & $\begin{array}{c}41 \\
(51.25 \%)\end{array}$ & $\begin{array}{c}6 \\
(7.5 \%)\end{array}$ & $\begin{array}{c}8 \\
(10.00 \%)\end{array}$ & $\begin{array}{c}10 \\
(12.50 \%)\end{array}$ & $\begin{array}{c}6 \\
(7.5 \%)\end{array}$ & $\begin{array}{c}4 \\
(5.00 \%)\end{array}$ & $\begin{array}{c}2 \\
(2.50 \%)\end{array}$ & $\begin{array}{c}1 \\
(1.25 \%)\end{array}$ & $\begin{array}{c}1 \\
(1.25 \%)\end{array}$ & $\begin{array}{c}1 \\
(1.25 \%)\end{array}$ \\
\hline
\end{tabular}

group ( $n=55,68.75 \%)$. Another 10 patients were from the rest of Lower Silesia, nonetheless, a significant group of patients ( $n=15,31.25 \%$ ) was from outside of this voivodeship. They were from adjacent Opole $(n=6)$ and Greater Poland $(n=4)$ voivodeships, and from surrounding Lesser Poland $(n=2)$, Silesia $(n=1)$, Lublin $(n=1)$ and even Germany $(n=1)$.

\section{Interventions and additional events}

During the whole programme 32 patients were qualified for surgical excision of the skin lesion (Figure 1), however, $7(21.88 \%, M: F, 3: 4)$ patients did not undergo the procedure. 5 of them broke off contact for unclear reasons and 2 did not come to the medical consultation despite the date agreed. In patients who were qualified to the procedure there were considerable distinctions in the different age groups of men and women ( $M-39.5, F-46.1)$. One

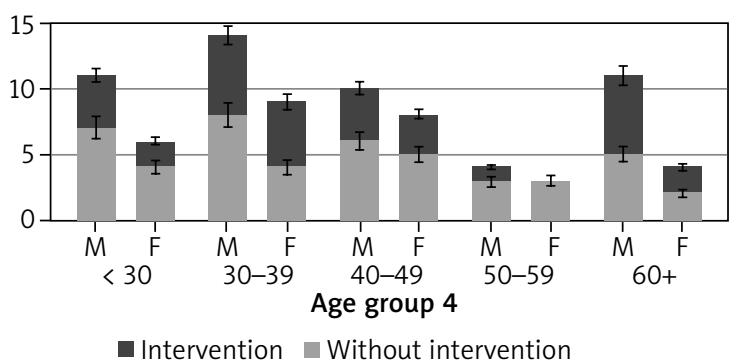

Figure 1. Structure of the study group by age and gender of the reasons was that there were more women $(n=6$, $30 \%)$ than men $(n=2,16.67 \%)$ over the age of 50 in each group, nevertheless, the difference was not statistically significant $(p=0.369)$ (Figure 2).

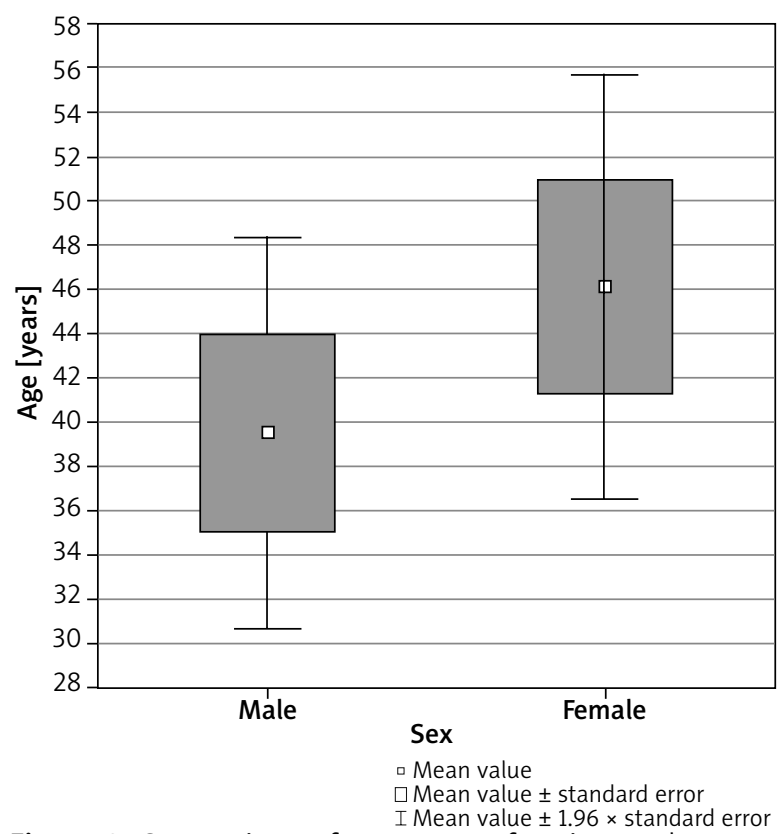

Figure 2. Comparison of mean age of patients who were qualified to the procedure 


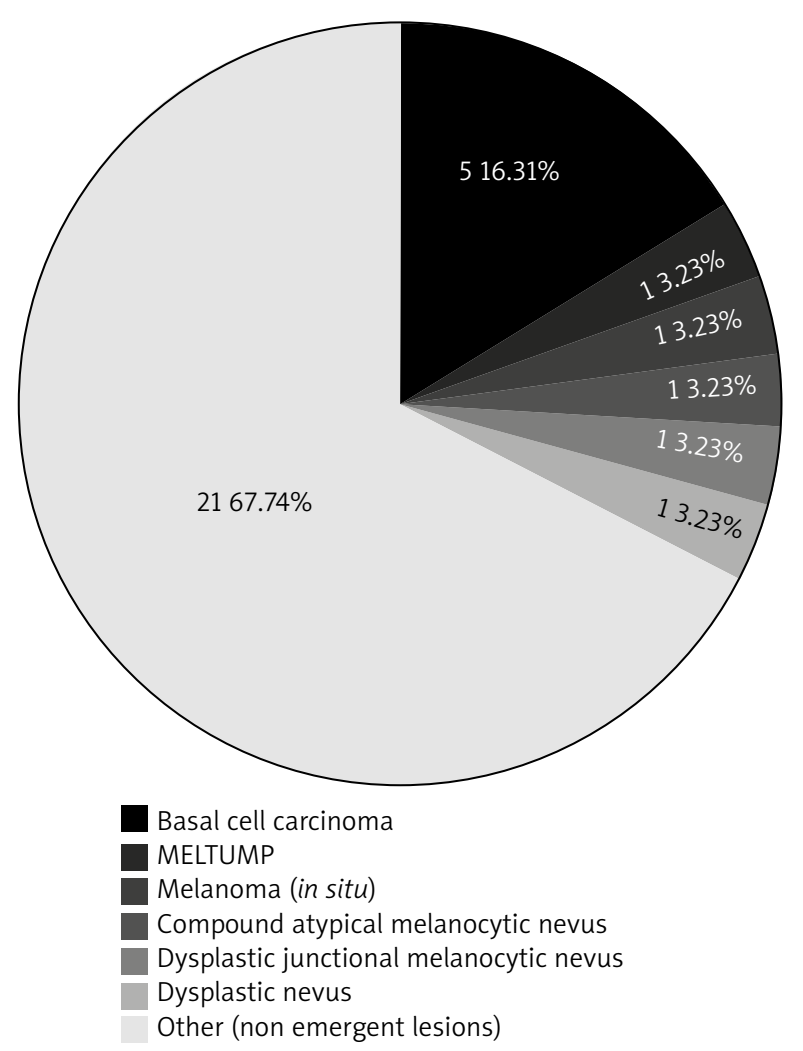

Figure 3. Results of the pathomorphological evaluation

Thirty-one lesions were excised in 25 patients and then evaluated histopathologically (Figure 3). In 4 of them the lesions were multiple, including 1 patient with double basal cell carcinoma (BCC). In total 10 lesions were considered emergent and in these cases urgent oncological care or extended diagnostics was introduced. This group included 5 BCCs, 3 dysplastic or anaplastic nevus, 1 melanocytic tumour of uncertain malignant potential (MELTUMP) and 1 melanoma in situ. All of them, except one, were completely resected. One benign lesion was excised partially due to the problematic localization in the temporal region. Among 21 benign lesions, the most numerous were different melanocytic nevus $(n=7$, $22.58 \%)$ and seborrheic wart $(n=6,19.35 \%)$. Among other, individual cases of schwannoma, dermatofibroma, neuronevus and blue nevus were observed. In these cases which did not require specialist care the treatment process ended after the excision of the lesions.

Furthermore, other incidents requiring urgent intervention or referral for additional diagnostics have occurred (Table 2). 4 dermatoscopies were performed by our team and for 2 patients dermatological recommendations were sent and self-control advised based on photographs. During the entire analysed period there were 3 paediatric patients, one of whom was referred for a paediatric surgery consultation. Moreover, 1 patient was recommended to consult an urologist and another
Table 2. Additional occurred accidents

\begin{tabular}{lc}
\hline Accident & $\begin{array}{c}\text { Cases } \\
(\mathrm{M}: \mathrm{F})\end{array}$ \\
\hline Dermatoscopy performed & $1: 3$ \\
\hline Recommendations sent and self-control advised & $0: 2$ \\
\hline Patient referred to a paediatric surgery & $1: 0$ \\
\hline Urological consultation recommended & $1: 0$ \\
\hline General surgeon consultation recommended & $1: 0$ \\
\hline
\end{tabular}

1 patient to consult a general surgeon due to the lack of dermatological indications. These cases were not directly related to the specificity of the dermatosurgical department, however, it exposed the problem of the access to professional advice from various fields of medicine during the COVID-19 pandemic.

\section{Discussion}

The COVID-19 pandemic is currently not only not diminishing but is actually on the rise. The number of infected and hospitalized patients is still growing despite the introduction of numerous national and international restrictions and recommendations [9]. This situation requires the reorganization of many hospitals and medical centres. This is evidenced also by the introduction of innovative projects designed to create modern diagnostic tools and treatment options for different groups of patients during the ongoing pandemic. This is reflected not only in activities such as trying to find an effective drug or vaccine or establishing recommendations for emergency surgeries, but also in implementing solutions to maintain the general operation process of each international individual healthcare system $[10,11]$.

Since the first months of the pandemic the remote assistance has become an important tool and, due to the technological advancement, its implementation was possible in a short time and used in many ways [12]. The idea of telemedical consultation in dermatology was introduced long before the COVID-19 outbreak and developed mainly in the form of wide-ranging preventive studies [13]. However, using teledermatology as a triage system seems interesting and may be used in favourable conditions against the pandemic [14].

Here, an important problem seems to be the further diagnosis and treatment of patients who suffer from other diseases, including those which are chronic and not related to COVID-19. During the pandemic a significant increase in the morbidity and the mortality of these diseases has been observed [15]. The progressing number of such patients is, among other, related to the involvement of the healthcare system in limiting the effects of a pandemic as well as a seemingly high risk of infection with the SARS-COV-2 in hospitals and during diagnostic procedures $[16,17]$. Patients with chronic and severe dis- 
eases are more prone to infection and potential complications, however, they could not interrupt their treatment, follow-up and diagnostic process [18]. The impact of fright of contamination of oneself or family members may partly explain why 11 out of the 80 patients enrolled in our study discontinued contact at various stages of the programme. The disproportions in age and gender in the whole group of patients are also worth mentioning. There were more women $(62.5 \%)$ in total and in each age group separately. It could be correlated with a greater tendency of women to consult the specialist and use of primary care [19]. Moreover, the life expectancy and the gender distribution by age in Poland is not equal, what was especially visible among patients over 60 years of age $(F: M=11: 4)$.

Due to the imposed restrictions and recommended social distancing the availability of primary healthcare professionals reduced [20]. During our programme, this problem was noticed. Patients were coming from different regions of Poland, even from Puławy which is located about $400 \mathrm{~km}$ away from Wroclaw. Moreover, there were patients who, despite the assumptions of the programme, were diagnosed with symptoms of the diseases unrelated directly to dermatology and were referred to other specialists. It indicates an urgent need to increase access to diagnostics.

Throughout the considered period of the programme 32 patients received information about the suspicious nature of their skin lesions. Ten lesions, including melanoma in situ, were assessed as requiring urgent intervention. In special cases, a supervision by an oncologist was recommended. The diagnoses of these patients may have been missed or delayed due to a lack of will or inability to come to hospital during the pandemic. Postponing the decision to start the diagnostic process, which is currently a serious problem due to the ongoing pandemic, may have consequences whereas early detection, especially in case of melanoma, has a significant impact on further treatment [21]. In addition to the benefits for patients, remote consultations may lower the costs generated by invasive treatment in the advanced stage of the disease $[22,23]$.

In the examination of a large number of patients, which grows with time of the pandemic, the algorithms and automated programs based on computer-aided diagnosis (CADx) and computer-aided detection (CAD) may be potentially useful in skin examination [24]. There is a multitude of applied methods and available solutions in dermatology which in the future may be another diagnostic tool [25]. The role of the CAD and CADx in the assessment of skin lesions is still controversial due to the subjective evaluation in classical skin examination depending on the experience of the physician. However, it may be appropriate to use IT techniques as "a filtering stage" to enhance the diagnostic process and to relieve the specialists' shortages [26].

\section{Conclusions}

In our paper we have shown that the first-line telemedical screening can be helpful in proper triage of patients with suspected skin lesions in the problematic COVID-19 era. Probably due to the fact of implementation of a simple and non-time-consuming data transfer methods it was possible to detect such a representative number of different skin cancers. This is especially important due to the fact that our study was performed in the group of patients which most likely due to the current pandemic situation, in the near future will not undergo any type of skin diagnostic and treatment processes. In our opinion, in the current pandemic situation the telemedical solutions should be more widely used in a group of patients who for different reasons cannot or do not wish to be consulted in the standard medical conditions. The authors, however, are fully aware that diagnosis based only on photos and a brief clinical description is insufficient and has much less diagnostic value than conventional screening programs or classic dermatoscopy. Therefore, the above methods should be used only in justified epidemic cases and patients should always remain under deferred standard close dermatological and oncological monitoring.

\section{Acknowledgments}

The study was conducted in the Second Department of Surgical Oncology (Wroclaw Comprehensive Cancer Center Wroclaw, Poland) and the work should be attributed to it. The head of the department is Marcin Ziętek MD, PhD.

\section{Conflict of interest}

The authors declare no conflict of interest.

\section{References}

1. Wierzbicki J, Nowacki M, Chrzanowska M, et al. Additive manufacturing technologies enabling rapid and interventional production of protective face shields and masks during the COVID-19 pandemic. Adv Clin Exp Med 2020; 29: 1021-8.

2. Anderson EJ, Rouphael NG, Widge AT, et al. Safety and immunogenicity of SARS-CoV-2 mRNA-1273 vaccine in older adults. N Engl J Med 2020; 383: 2427-38.

3. Orlandi M. The systemic sclerosis patient in the COVID-19 era: the challenging crossroad between immunosuppression, differential diagnosis and long-term psychological distress. Clin Rheumatol 2020; 39: 2043-7.

4. Mauro V, Lorenzo M, Paolo C, Sergio H. Treat all COVID 19-positive patients, but do not forget those negative with chronic diseases. Intern Emerg Med 2020; 15: 787-90.

5. Mann DM, Chen J, Chunara R, et al. COVID-19 transforms health care through telemedicine: evidence from the field. J Am Med Inform Assoc 2020; 27: 1132-5.

6. Brunasso AMG, Massone C. Teledermatologic monitoring for chronic cutaneous autoimmune diseases with smartwork- 
ing during COVID-19 emergency in a tertiary center in Italy. Dermatol Ther 2020; 33: e13495.

7. Tagliaferri L, Di Stefani A, Schinzari G, et al. Skin cancer triage and management during COVID-19 pandemic. J Eur Acad Dermatol Venereol 2020; 34: 1136-9.

8. Vanni G, Materazzo M, Pellicciaro M, et al. Breast cancer and COVID-19: the effect of fear on patients' decision-making process. In Vivo 2020; 34 (3 Suppl): 1651-9.

9. Nicola M, Alsafi Z, Sohrabi C, et al. The socio-economic implications of the coronavirus pandemic (COVID-19): a review. Int J Surg 2020; 78: 185-93.

10. De Simone B, Chouillard E, Di Saverio S, et al. Emergency surgery during the COVID-19 pandemic: what you need to know for practice. Ann R Coll Surg Engl 2020; 102: 323-32.

11. Kannan S, Shaik Syed Ali P, Sheeza A, Hemalatha K. COVID-19 (novel coronavirus 2019) - recent trends. Eur Rev Med Pharmacol Sci 2020; 24: 2006-11.

12. Jnr BA. Use of telemedicine and virtual care for remote treatment in response to COVID-19 pandemic. J Med Syst 2020; 44: 132.

13. Eminović N, de Keizer NF, Bindels PJ, Hasman A. Maturity of teledermatology evaluation research: a systematic literature review. Br J Dermatol 2007; 156: 412-9.

14. Massone C, Maak D, Hofmann-Wellenhof R, et al. Teledermatology for skin cancer prevention: an experience on 690 Austrian patients. J Eur Acad Dermatol Venereol 2014; 28 : 1103-8.

15. Czeisler MÉ, Marynak K, Clarke KEN, et al. Delay or avoidance of medical care because of COVID-19-related concerns - United States, June 2020. MMWR Morb Mortal Wkly Rep 2020; 69: 1250-7.

16. Mantica G, Riccardi N, Terrone C, Gratarola A. Non-COVID-19 visits to emergency departments during the pandemic: the impact of fear. Public Health 2020; 183: 40-1.

17. Lazzerini M, Barbi E, Apicella A, et al. Delayed access or provision of care in Italy resulting from fear of COVID-19. Lancet Child Adolesc Health 2020; 4: e10-1.

18. Liu N, Huang R, Baldacchino T, et al. Telehealth for noncritical patients with chronic diseases during the COVID-19 pandemic. J Med Internet Res 2020; 22: e19493.

19. Hunt K, Adamson J, Hewitt C, Nazareth I. Do women consult more than men? A review of gender and consultation for back pain and headache. J Health Serv Res Policy 2011; 16: 108-17.

20. Chudasama YV, Gillies CL, Zaccardi F, et al. Impact of COVID-19 on routine care for chronic diseases: a global survey of views from healthcare professionals. Diabetes Metab Syndr 2020; 14: 965-7.

21. Janda M, Horsham C, Koh U, et al. Redesigning skin cancer early detection and care using a new mobile health application: protocol of the SKIN Research Project, a Randomised Controlled Trial. Dermatology 2019; 235: 11-8.

22. van der Heijden JP, de Keizer NF, Bos JD, et al. Teledermatology applied following patient selection by general practitioners in daily practice improves efficiency and quality of care at lower cost. Br J Dermatol 2011; 165: 1058-65.

23. Pala P, Bergler-Czop BS, Gwiżdż JM. Teledermatology: idea, benefits and risks of modern age - a systematic review based on melanoma. Adv Dermatol Allergol 2020; 37: 159-67.

24. Celebi ME, Kingravi HA, Uddin B, et al. A methodological approach to the classification of dermoscopy images. Comput Med Imaging Graph 2007; 31: 362-73.

25. Pathan S, Prabhu KG, Siddalingaswamy PC. Techniques and algorithms for computer aided diagnosis of pigmented skin lesions - a review. Biomedical Signal Processing and Control 2018; 39: 237-62.

26. Chuchu N, Takwoingi Y, Dinnes J, et al. Smartphone applications for triaging adults with skin lesions that are suspicious for melanoma. Cochrane Database Syst Rev 2018; 12: CD013192. 